\title{
Renewable energy based dynamic tariff system for domestic load management
}

\author{
Kuheli Goswami ${ }^{1}$, Arindam Kumar Sil ${ }^{2}$ \\ ${ }^{1}$ Department of Electrical Engineering, Maulana Abul Kalam Azad University of Technology, Kolkata, India \\ ${ }^{2}$ Department of Electrical Engineering, Jadavpur University, Kolkata, India
}

\begin{tabular}{l} 
Article Info \\
\hline Article history: \\
Received Mar 7, 2021 \\
Revised Nov 25, 2021 \\
Accepted Dec 8, 2021 \\
\hline
\end{tabular}

Keywords:

AEMS

ARIMAX

Energy management

Genetic algorithm

HGPSO

Particle swarm optimization

Three-part tariff

\begin{abstract}
To deal with the present power-scenario, this paper proposes a model of an advanced energy management system, which tries to achieve peak clipping, peak to average ratio reduction and cost reduction based on effective utilization of distributed generations. This helps to manage conventional loads based on flexible tariff system. The main contribution of this work is the development of three-part dynamic tariff system on the basis of time of utilizing power, available renewable energy sources (RES) and consumers' load profile. This incorporates consumers' choice to suitably select for either consuming power from conventional energy sources and/or renewable energy sources during peak or off-peak hours. To validate the efficiency of the proposed model we have comparatively evaluated the model performance with existing optimization techniques using genetic algorithm and particle swarm optimization. A new optimization technique, hybrid greedy particle swarm optimization has been proposed which is based on the two aforementioned techniques. It is found that the proposed model is superior with the improved tariff scheme when subjected to load management and consumers' financial benefit. This work leads to maintain a healthy relationship between the utility sectors and the consumers, thereby making the existing grid more reliable, robust, flexible yet cost effective.
\end{abstract}

This is an open access article under the $\underline{\text { CC BY-SA license. }}$

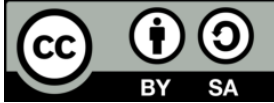

\section{Corresponding Author:}

Kuheli Goswami

Department of Electrical Engineering, Maulana Abul Kalam Azad University of Technology

Kolkata, India

Email:kgg2017juresearch@gmail.com

\section{INTRODUCTION}

A smart and intelligent energy management system is required to address the difference between generation and demand. There is a large volume of published studies describing the role of demand side management (DSM) in power system planning. Over the past decade, most research in this issue have emphasized the use of renewable energy sources (RES) and incline block tariff. These can be observed in the DSM approaches proposed by some authors [1]-[3]. Application of load management as an effective technique for handling the peak load management issues can be observed in the work of Logenthiran and Srinivasan [4]. However, for applying this solution in the practical work, peak load management cannot be the sole criteria. Incorporation of several other factors such as consumers satisfaction level and cost of energy are also required for developing an efficient energy management system (EMS) which has been demonstrated by the work of $\mathrm{Xu}$ et al. [5]. In recent days RES has gained importance in energy management system. authors in [6], [7], conclusively agreed to this and explained how by dispatching the shiftable domestic loads and available storage resources energy management solution can be achieved. In addition to the widely used RES, biomass can be used for self-generation in rural areas has been proposed by Naz et al. [8]. Despite the 
simplicity of these models, Issi and Kaplan in [9] and Ahmad et al. in [10] found that it is necessary to determine the load profiles and power consumptions of home appliances individually for scheduling the load judiciously, which in turn helps to formulate a residential energy management problem under various practical constraints like human interaction, unavailable power supply and consumer preference. In contrast, Malik et al. in [11] and Nguyen et al. in [12] indicated that beside RES integration and load scheduling, efficient communication and optimization scheme is utmost important. Similarly, authors in [13]-[15] discussed several methodologies and future techniques to optimize energy consumption with minimum consumer interaction. Another possibility would be trading of self-generation among the prosumers and consumers which can help to increase grid stability [16]. Similarly, a contract-based energy trading scheme has been proposed by Zhang et al. [17] and the economic impact of demand response has been discussed by Conchado and Linares [18]. Several DSM approaches based on real time pricing has been proposed by the authors in their research articles [19], [20]. However, a number of studies [21] show that there are numerous challenges and restrictions in implementations of DSM. Even Govt. of India has taken various actions to implement DSM strategies [22]. Despite the numerous works carried out, mentioned in Table 1, no previous study has thoroughly investigated and analysed the consumers preference on the basis of RES availability and load profile. On the other hand, a search of the literature revealed that limited studies have focused on load analysis and tariff system. Since the impact of tariff on EMS is understudied, there is a need to develop an improved tariff system based on time of utilizing power, available RES and consumers' load profile.

Table 1. Summarized related work

\begin{tabular}{|c|c|c|c|}
\hline Techniques & Aims & Attributes & Limitations \\
\hline EA [4] & Cost reduction & $\begin{array}{l}\text { Energy optimization in industrial, } \\
\text { commercial and residential sectors }\end{array}$ & Complex system \\
\hline GA [23] & Cost reduction & $\begin{array}{l}\text { Optimization of energy } \\
\text { consumption }\end{array}$ & $\begin{array}{l}\text { Complex system and Consumers' } \\
\text { preference is ignored }\end{array}$ \\
\hline FP [24] & Cost reduction & Cost effective model with DG & $\begin{array}{l}\text { PAR and Consumers' preference } \\
\text { not considered }\end{array}$ \\
\hline GA [25] & Cost and PAR reduction & Generic model & Consumers' preference is ignored \\
\hline BPSO [26] & $\begin{array}{l}\text { Cost and PAR reduction } \\
\text { considering consumers' } \\
\text { preference }\end{array}$ & Efficiency of BPSO & $\begin{array}{l}\text { Time slots are divided into sub } \\
\text { time slots, which is complex }\end{array}$ \\
\hline $\begin{array}{l}\text { Hybrid Technique } \\
\text { (LP and BPSO) [27] }\end{array}$ & $\begin{array}{l}\text { Cost reduction considering } \\
\text { consumers' preference }\end{array}$ & DAP model & PAR reduction not achieved \\
\hline $\begin{array}{l}\text { GA, BPSO, ACO } \\
{[28]}\end{array}$ & $\begin{array}{l}\text { Cost and PAR reduction } \\
\text { considering consumers' } \\
\text { preference }\end{array}$ & $\begin{array}{l}\text { Load scheduling by considering } \\
\text { consumers' preference and RES }\end{array}$ & $\begin{array}{l}\text { Complex system and better } \\
\text { management are possible }\end{array}$ \\
\hline GA [29] & Cost and PAR reduction & $\begin{array}{l}\text { Model tested using radial residential } \\
\text { network }\end{array}$ & $\begin{array}{l}\text { Complex system and better } \\
\text { management are possible }\end{array}$ \\
\hline GA [30] & $\begin{array}{l}\text { Cost reduction considering } \\
\text { consumers' preference }\end{array}$ & $\begin{array}{l}\text { Optimization of energy } \\
\text { consumption on the basis of RES } \\
\text { availability }\end{array}$ & PAR reduction not achieved \\
\hline DP [31] & Cost and PAR reduction & $\begin{array}{l}\text { Optimization of energy } \\
\text { consumption on the basis of RES } \\
\text { availability }\end{array}$ & $\begin{array}{l}\text { Complex system and Consumers' } \\
\text { preference is ignored }\end{array}$ \\
\hline ILP [32] & Cost and PAR reduction & $\begin{array}{l}\text { Load analysis using Day Ahead } \\
\text { Pricing (DAP) }\end{array}$ & PAR reduction not achieved \\
\hline $\begin{array}{l}\text { Hybrid Technique } \\
\text { (GA and PSO) [33] }\end{array}$ & Cost and PAR reduction & Considered Energy Storage System & Consumers' preference is ignored \\
\hline GHSA [14] & $\begin{array}{l}\text { Cost and PAR reduction } \\
\text { considering consumers' } \\
\text { preference }\end{array}$ & $\begin{array}{l}\text { Analysis on the basis of Single and } \\
\text { Multiple Homes }\end{array}$ & $\begin{array}{l}\text { System is complex and time } \\
\text { consuming }\end{array}$ \\
\hline PSO [34] & Cost and PAR reduction & Efficient use of RES & Consumers' preference is ignored \\
\hline
\end{tabular}

In view of these shortcomings, an advanced energy management system (AEMS) has been proposed in this paper. The current study contributes to the expansion of the knowledge in this field by addressing four important issues. First, electricity cost has been reduced by introducing advanced three-part dynamic tariff structure. Second, grid stability has been maintained by minimizing peak to average ratio (PAR). Third, peak demand has been addressed by load shifting and valley filling. Fourth, consumer comforts and benefits have been maximized by integrating RES and designing a user-friendly application. Thereby an effective load management system based on load scheduling has been proposed which in turn encourages renewable energy usage reducing the adverse effects of carbon emission and ensures proper utilization of electrical power incorporating an advanced tariff structure. 


\section{PROBLEM FORMULATION}

Identifying the gaps in the aforementioned literature work, we proposed a novel AEMS with RES integration to reduce PAR and electricity cost at user end, which is based on critical load analysis, consumers comfort level and proposed dynamic tariff structure. Secondly, we evaluated the proposed AEMS by performing extensive case studies and simulations. First, we applied multi-objective optimization techniques based on genetic algorithm (GA) and particle swarm optimization (PSO) to reach the optimum energy management solution. Further we analysed our AEMS with the effects of proposed three-part dynamic tariff structure. In addition, based on a hybrid combination of genetic algorithm and particle swarm optimization a new optimization technique has been proposed and found to perform better than the existing optimization techniques. Based on these aforementioned steps, an AEMS has been designed, developed and tested.

\section{AEMS ARCHITECTURE}

For efficient energy management with the existing grid, AEMS is of utmost important. According to utility perspective the primary task of AEMS is to manage the energy consumption, thereby reducing PAR and in consumers' perspective, it is to reduce cost of electricity. Here we have designed a model in matrix laboratory simulation and link (MATLAB/Simulink) platform considering five residential consumers with different load patterns. The utility companies sends useful day ahead forecasted information such as demand profile, tariff and also availability of RES through a smart application. This Microsoft.Net technology-based application has been developed for the benefit of the consumers so that they can plan their electricity usage based on their comforts and preferences. At the same time the application itself will suggest the most optimal solution to adopt for domestic consumers. A new advanced and flexible dynamic tariff structure has been proposed to ensure consumers preference. Based on the proposed tariff an optimum point has been achieved where usage of conventional energy and renewable energy results in reasonable electricity pricing and significant reduction in PAR.

Therefore, rest of this paper has been organised as shown in Figure 1. In section 3, modelling of different parts of the system will be discussed such as: i) demand forecasting, ii) RES and ESS, iii) proposed tariff, iv) Heuristic algorithm for optimization, and v) energy consumption model respectively. In section 4 and 5, we will present and discuss the results and conclusion respectively.

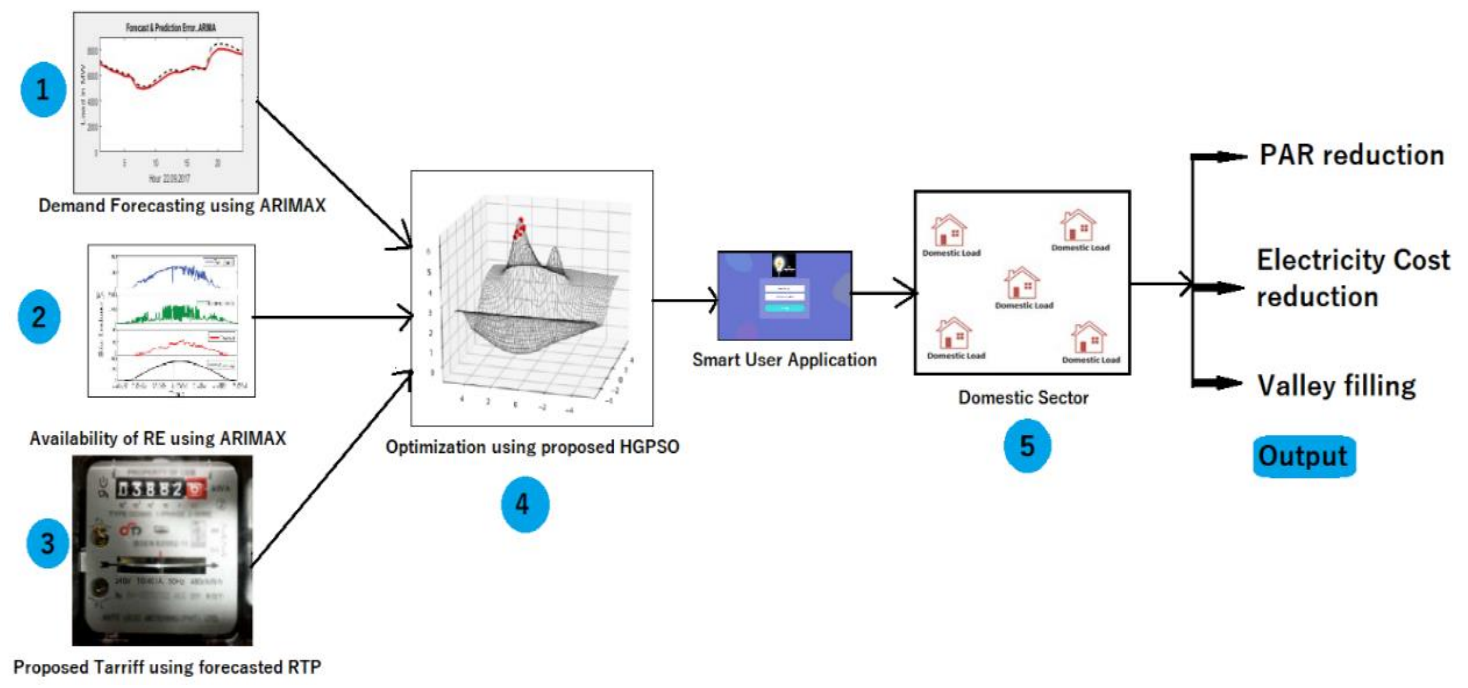

Figure 1. System modelling

\section{SYSTEM MODELLING}

The proposed AEMS incorporates the use of photovoltaic (PV) system as RES and energy storage system (ESS) to store electricity either from main grid at low price time or from RES for home appliances at peak price time. This in turn helps to reduce the carbon emission level. The entire system can be briefly described using a block diagram as shown in Figure 2. 


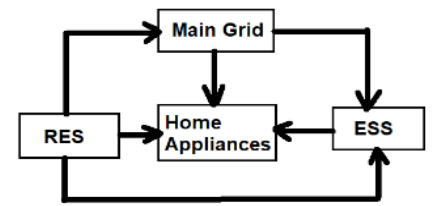

Figure 2. Basic block diagram of system

\subsection{Demand forecasting}

Demand forecasting is the initial and most important part of electrical power system, specifically load management system [35]. In this article, we have compared different forecasting tool and finally used auto regressive integrated moving average with exogenous variables (ARIMAX), a multivariate method to perform load forecasting, which is performing comparatively better than other techniques [36]. By using this classical method, we have achieved an almost error free forecasted demand profile [37], [38].

Auto regressive integrated moving with exogenous variables, here to design ARIMAX model for forecasting Yt and $\mathrm{Xt}$ have been considered as two stationary time series. The transfer function model (TFM) can be written as,

$$
Y_{t}=C+v(B) X_{t}+N_{t}
$$

where, Yt is response series, $\mathrm{Xt}$ is predictor data series, $\mathrm{C}$ is constant term, $\mathrm{N}_{\mathrm{t}}$ is the stochastic disturbance, $v(B) X_{t}$ is the transfer function and $\mathrm{B}$ is back shift operator.

$$
v(B) X_{t}=\left(v_{0}+v_{1} B+v_{2} B^{2}+\cdots+v_{k} B^{k}\right) X_{t}
$$

In ARIMAX, we deal with two different time series Xt and Yt. The Transfer Function can be written as,

$$
v(B) X_{t}=\left[\frac{w_{h}(B) B^{b}}{\delta_{r}(B)}\right] X_{t}
$$

theoretically, $v(B) X_{t}$ has infinite number of coefficients. Where,

$$
\begin{aligned}
& w_{h}(B)=w_{0}+w_{1} B+\cdots \\
& \delta_{r}(B)=1-\delta_{1}(B)-\cdots-\delta_{r} B^{r}
\end{aligned}
$$

where, $\mathrm{h}$ is the number of terms plus one of the independent variables, $\mathrm{r}$ is the number of terms plus one of the dependent variables and $b$ is the dead time.

$$
\text { Nt can be written as, } N_{t}=\left[\frac{\theta(B) \Theta\left(\mathrm{B}^{\mathrm{S}}\right)}{\phi(\mathrm{B}) \phi\left(B^{S}\right)(1-B)^{d}\left(1-B^{S}\right)^{D}}\right] a_{t}
$$

Where, at is zero mean and normally distributed white noise. Therefore, TFM can be finally expressed as,

$$
Y_{t}=C+\left(v_{0}+v_{1} B+v_{2} B^{2}+\cdots+v_{k} B^{k}\right) X_{t}+\left[\frac{\theta(B) \Theta\left(\mathrm{B}^{\mathrm{S}}\right)}{\phi(\mathrm{B}) \phi\left(\mathrm{B}^{\mathrm{S}}\right)(1-B)^{d}\left(1-B^{S}\right)^{d}}\right] a_{t}
$$

initially, the value of $\mathrm{K}$ and $\mathrm{Nt}$ must be specified to find out (b, r, h). By observing and comparing the estimated impulse response function with some common theoretical functions $(\mathrm{b}, \mathrm{r}, \mathrm{h})$ can also be identified to represent TFM. Several diagnostic checks are involved to check the status of residuals in the series and to conclude whether the model is adequate or not. Akaike information criterion (AIC) is one of them. A forecasting model is highly acceptable if the value of Akaike's information criterion is small. Bayesian information criterion (BIC) and Schwarz information criterion (SIC) are also very effective in choosing the accurate model.

\subsection{Availability of RES}

Availability of RES: We assume that some of the consumers are equipped with PV system. We have used the given mathematical model to calculate the PV output $\left(\mathrm{P}_{\mathrm{PV}}\right)$ at $\mathrm{t}$. 


$$
P_{P V}(\mathrm{~T})=G H I(t) \cdot A \cdot \eta \forall t 0 \leq \mathrm{T} \leq 24
$$

Where global horizontal irradiation $(\mathrm{GHI})$ is $(\mathrm{kW} / \mathrm{m} 2)$. A is the area of solar panel and $\eta$ is the efficiency of the PV system. The electrical energy generated (EPV) by the PV system in time duration $\Delta \mathrm{t}$,

$$
E_{P V}(t)=P_{P V}(\mathrm{~T}) \cdot \Delta t
$$

where $\mathrm{T}$ is the real time. This energy will be used for home appliances $\left(E_{P V . l o a d}\right)$ and energy storage $\left(E_{P V \text {.storage }}\right)$.

$$
\begin{aligned}
& E_{P V}(t)=E_{P V . l o a d}(t)+E_{P V . s t o r a g e}(t) \\
& \text { Constraints: } 0 \leq E_{P V . l o a d}(t) \leq G H I(t) \cdot A \cdot \eta \cdot \Delta t \\
& 0 \leq E_{P V \text {.storage }}(t) \leq G H I(t) \cdot A \cdot \eta \cdot \Delta t
\end{aligned}
$$

\subsection{Energy storage system (ESS)}

The aim of ESS is to use RES and main grid electricity efficiently. ESS acts as a sink to store energy from RES and main grid at low price time and source for domestic appliances. The mathematical model of ESS is,

$$
\begin{aligned}
& E_{E S S . d i s c h a r g e}(t)=E_{E S S . l o a d}(t)\left(1-\operatorname{mode}_{E S S}(t)\right) \\
& E_{\text {ESS.charge }}(t)=\left(E_{\text {RES.charge }}(t)+E_{\text {MG.charge }}(t)\right) \cdot \operatorname{mode} e_{E S S}(t) \\
& \operatorname{mode}_{E S S}(t)=\left\{\begin{array}{c}
1, \text { if ESS is charged } \\
0, \text { if ESS is discharged }
\end{array}\right. \\
& E_{\text {ESS.level }}(t)=E_{\text {ESS.level }}(t-1)+E_{\text {ESS.charge }}(t) . \eta_{E S S}-E_{\text {ESS.discharge }}(t) / \eta_{\text {ESS }}
\end{aligned}
$$

here $E_{E S S . l e v e l}$ is the energy level of ESS after time $t$ and $\eta_{E S S}$ efficiency of ESS.

As we are considering our system as a day ahead system, therefore energy level of ESS must return to the initial level $\left(E L_{0}\right)$ at the end of the day.

$$
\operatorname{ESS}_{\text {level }}(t)=E L_{0}
$$

Constraints: The ESS charge/discharge rate should not exceed the critical value and charge level of ESS should lie between minimum (EL_min ) and maximum energy level (EL_max).

\subsection{Energy consumption model}

AEMS depends on several factors such as demand profile, availability of renewable energy, judicious tariff structure, consumers' flexible attitude and their direct participation in electricity trade market. Here, we have considered five different consumers and each home with set of appliances $\mathrm{A}$ and $\mathrm{N}$ is the total number of appliances. a1, a2, ... aN are $\mathrm{N}$ number of domestic appliances used in a home. They are operated over a time period $t \in \mathrm{T}$, where Suppose, Sal is the starting time instants of appliance al and Fa1 is the finishing time instants of appliance a1. Therefore, operation time interval for scheduled appliances a1 is $\left[\mathrm{S}_{\mathrm{a} 1}, \mathrm{~F}_{\mathrm{a} 1}\right]$.

$$
\begin{aligned}
& \mathrm{A} \triangleq\{\mathrm{a} 1, \mathrm{a} 2, \mathrm{a} 3, \ldots \ldots \ldots \ldots \ldots \ldots, \mathrm{aN}\} \\
& \mathrm{T} \triangleq\{1,2,3, \ldots \ldots \ldots \ldots \ldots \ldots \ldots, 24\}
\end{aligned}
$$

Here, in this model we have considered conventional energy sources (CES) and RES to satisfy the demand. We have assumed, $\epsilon_{t . P V}$ as generated or available solar energy at time $\mathrm{t}$, which should be known or forecasted. However, the price of the renewable energy is variable. Here, $\gamma$ t.MG is denoting forecasted price of energy from main grid at time t, $\gamma$ t.PV is denoting forecasted price of solar energy at time t.

We have considered $\psi \mathrm{a} 1$ as the operation time vector of appliance a1. Therefore,

$$
\psi \mathrm{a} 1=\left[\beta_{1 \mathrm{Ga} 1}, \beta_{1 \mathrm{PVa} 1}, \beta_{2 \mathrm{Ga} 1}, \beta_{2 \mathrm{PVa} 1}, \ldots \ldots, \beta_{24 \mathrm{Ga} 1}, \beta_{24 \mathrm{PVa} 1}\right]
$$


$\beta_{\mathrm{tGa}}$ is used grid energy to satisfy demand of a1 at time $\mathrm{t}$ (known/forecasted).

$\beta_{\mathrm{tPVa} 1}$ is used solar energy to satisfy demand of a1 at time $\mathrm{t}$ (known/forecasted).

State of operation of an appliance a1 at time,

$$
\mathrm{t}, \phi_{\mathrm{a} 1}(\mathrm{t})=\left\{\begin{array}{c}
0 \text { when appliance is not operating } \\
1 \text { when appliance is operating }
\end{array}\right.
$$

Consumer will place a day ahead request for a1 appliance in time interval [Sa1, Fa1], where [Sa1, Fa1] $\epsilon$ T. Consumer needs to specify $\alpha$ a and fa for availing the best suited tariff scheme. Here fal is the no. of switching ON of appliance a1. Total energy demand of a1 can be satisfied by CES and RES. Hence the total energy consumed by al can be determined as,

$$
\sigma_{a 1}=\sum_{t=1}^{T} \sum_{a_{1} \in \mathrm{A}} \alpha_{a 1}\left(\beta_{G a 1}+\beta_{P V a 1}\right)
$$

similarly, the cost of the energy consumed by a1 over 24 hours can be calculated as,

$$
\delta_{a 1}=\sum_{t=1}^{T} \sum_{a_{1} \in \mathrm{A}} \alpha_{a 1}\left(\gamma_{G}^{t} \beta_{G a 1}^{t}+\gamma_{P V}^{t} \beta_{P V a 1}^{t}\right)
$$

\subsection{Load categorization}

In this section, domestic consumers have been classified as active consumers and passive consumers. Active consumers are equipped with PV system and ESS, whereas passive consumers are equipped with ESS only. The domestic loads further can be categorized based on their power consumption, operation time, number of switching ON-OFF over 24 hours and consumer preferences. They are classified as: i) interruptible loads, ii) non-interruptible loads, and iii) interruptible loads with minimum delay.

Here power consumption of different domestic loads such as refrigerator, washing machine, induction oven, iron, fan, light, computer, and television has been discussed and analysed in detail for different operating modes which has been shown in Figure 3.

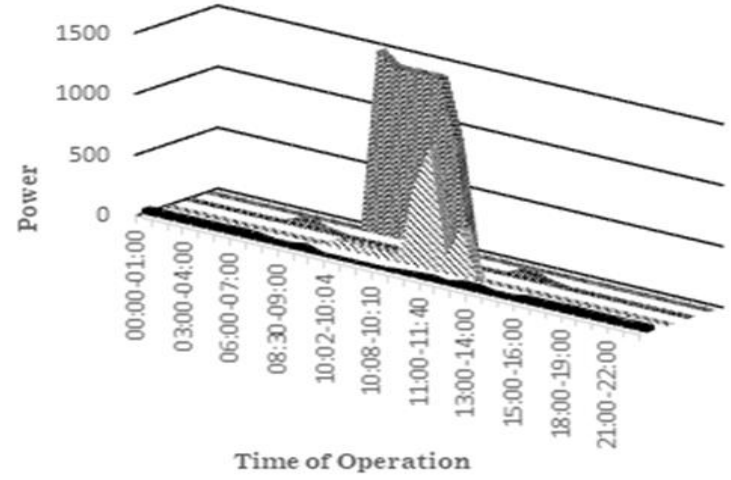

Figure 3. Power consumption of different home appliances

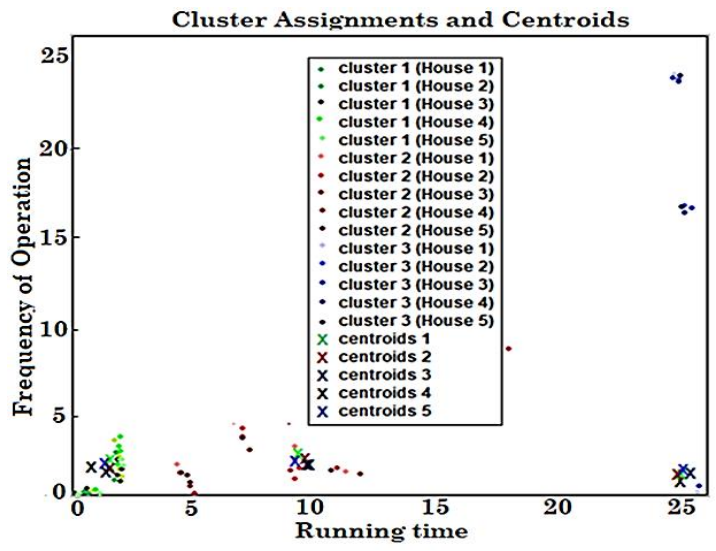

Figure 4. Categorization of domestic loads for 5 households using K-means clustering

Here, the K-means clustering technique has been used to prioritize the loads. Figure 4 is showing the clusters based on which the loads are marked with their priority ranking for five different domestic consumers respectively. The clustering result has been verified again using a mathematical model. Suppose, request time of the appliance a1 is $\tau_{r a 1}$ and waiting time of the appliance al is $\tau_{w a 1}$.

Therefore, $\tau_{w a 1}=S_{a 1}-\tau_{r a 1}$

Total waiting time, $\tau \mathrm{w}=\sum_{i=1}^{N} \tau_{\mathrm{wai}}$

Average waiting time, $\tau \mathrm{w} \cdot \operatorname{avg}=\tau \mathrm{w} / \mathrm{N}$

Here, we have considered $\alpha$ ai as the rating of appliance ai where $\mathrm{i}=\{1,2,3, \ldots \ldots, \mathrm{N}\}, \rho_{a 1}^{t}$ as the operating time of a1 over 24 hours and fal as the frequency of operation of a1 or No. of switch ON. 


$$
\begin{aligned}
& \rho_{a 1}^{*}=\frac{\text { time of run }}{\text { No.of switch ON }} \\
& \rho_{a 1}^{*}=\rho_{a 1}^{t} / f_{a 1} \\
& \rho_{a i}^{*}=\sum_{t=1}^{24} \sum_{a_{1} \in A} \delta_{a i}^{t} / f_{a i} \forall \text { ai } \in \mathrm{A} \\
& \text { Utilization factor, } U_{a i}=\frac{1}{24} \sum \rho_{a i}^{t} \\
& \text { Priority Ranking, } \vartheta_{a i}=\left[U_{a i}\right] *\left[\rho_{a i}^{*}\right] \forall \text { ai } \in \mathrm{A}
\end{aligned}
$$

Based on this ranking finally the load has been categorized as non-interruptible load, interruptible load with minimum delay time and interruptible load.

\subsection{Proposed tariff structure}

Several tariff models are available to define electricity prices for a day. Amongst these, time of use (ToU) tariff model is used to define the electricity price on the basis of time of use in a day, whereas critical peak pricing (CPP) and critical peak rebate (CPR) are variants of ToU. Another tariff structure, real time pricing (RTP) defines the utility cost of supplying electricity at a specific time. In this section, we have proposed a three-part dynamic tariff (C) structure, which is based on ToU, CPP, CPR and RTP.

$$
C=\alpha+\beta x+\gamma(x t)
$$

Here, $\alpha$ comprises of meter rent and monthly variable cost adjustment (MVCA). is a fixed charge independent of maximum demand and energy consumption. $\beta$ depends on maximum demand (kVA) or sanctioned demand $(\mathrm{kVA}) . \gamma$ depends on energy consumption $(\mathrm{kWh})$.

$$
\gamma=\gamma_{C E S}+\gamma_{R E S}
$$

Here, $\gamma_{C E S}$ is the cost of energy from main grid and $\gamma_{R E S}$ is the cost of renewable energy which is fixed cost.

$$
\gamma_{C E S}=\left\{\begin{array}{c}
\gamma_{1 . C E S} \text { Moderate pricing hour }(06: 00 \mathrm{am}-05: 00 \mathrm{pm}) \\
\gamma_{2 . C E S} \text { Peak pricing hour }(05: 00 \mathrm{pm}-11: 00 \mathrm{pm}) \\
\gamma_{3 . C E S} \text { Low pricing hour }(11: 00 \mathrm{pm}-06: 00 \mathrm{am})
\end{array}\right.
$$

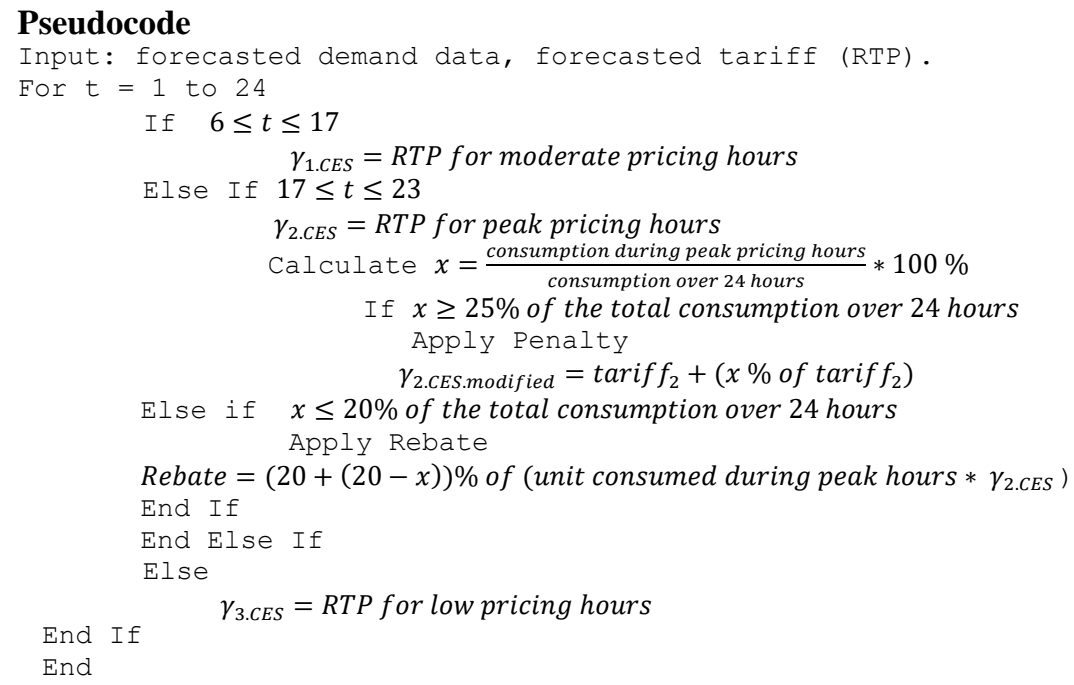

\subsection{Heuristic algorithm}

The demand profiles of domestic consumers depend on geographical conditions and demography. Keeping in view this fact, due to highly volatile behaviour of consumers and intermittent characteristics of RESs, we have dealt with different heuristic algorithms. Here, a hybrid optimization technique based on GA and PSO has been developed which follows greedy selection technique and can be used for personal best and global best solution. It has been represented as hybrid greedy particle swarm optimization (HGPSO). We have used multiple knapsack problem (MKP) to balance the demand and supply and HGPSO to reach optimum point. 


\section{Pseudocode}

Input: Fitness function (based on RES availability, Tariff and Consumers' comfort), lb, ub, Population Size, NP (based on home appliances), T (terminating criteria).

Evaluate the objective function value (f) of $P$

Assign Pbest and fpbest

Identify the solution as best fitness and assign that solution as gbest and fitness as fgbest.

For $t=1$ to $T$

For $i=1$ to $\mathrm{NP}$

Determine the velocity of ith particle

Determine the new position of ith particle

Bound position

Evaluate the objective function value

Update the population

Update Pbest, $i$ and fpbest

Update gbest and fgbest

End

Combine $\mathrm{P}$ and Pbest to perform $(\mu+\lambda)$ for selecting $\mathrm{P}$ in next iteration

End

Repeat $\mathrm{T}$ iterations

\section{RESULTS AND DISCUSSION}

Based on the data obtained from physical survey and online survey an efficient model has been designed in MATLAB/Simulink platform which has been analyzed on the basis of proposed optimization technique to figure out the improvements over the existing system. The efficiency of the model has also been analyzed in the following sections based on the consumers' and utility sector's perspective. This can further be categorized as monthly electricity bill, waiting time and PAR, peak demand respectively.

\subsection{Consumers' preference}

\subsubsection{Monthly electricity bill}

Total energy cost in our system has been reduced based on two parameters: i) flexible and efficient use of RES and ESS and ii) proposed dynamic tariff. Consumers need to either declare their load requirement with the ratings of the appliances a day ahead or they can follow the suggested demand profile by the utility company. They can choose and declare the best suited tariff plan a day ahead. Using this approach consumers will get maximum benefits as shown in Figures 5(a) and 5(b) and Table 2.

Table 2. The performance of AEMS on the basis of monthly electricity bill

\begin{tabular}{cccc}
\hline \multirow{2}{*}{ Consumers } & \multicolumn{2}{c}{ Monthly Electricity Expense } & \multirow{2}{*}{ Savings in Monthly Electricity Expense (in \%) } \\
& Without AEMS & With HGPSO AEMS & 32 \\
\hline Household 1 & $3,597.80$ & $2,440.55$ & 24 \\
Household 2 & $2,203.21$ & $1,664.81$ & 36 \\
Household 3 & $2,332.15$ & $1,499.10$ & 26 \\
Household 4 & $1,852.41$ & $1,371.00$ & 29 \\
Household 5 & $3,953.67$ & $2,810.47$ &
\end{tabular}

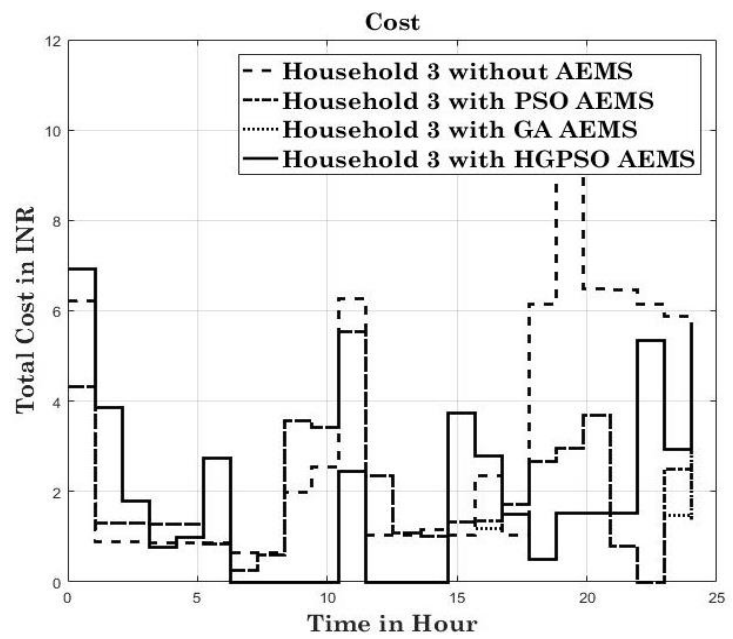

(a)

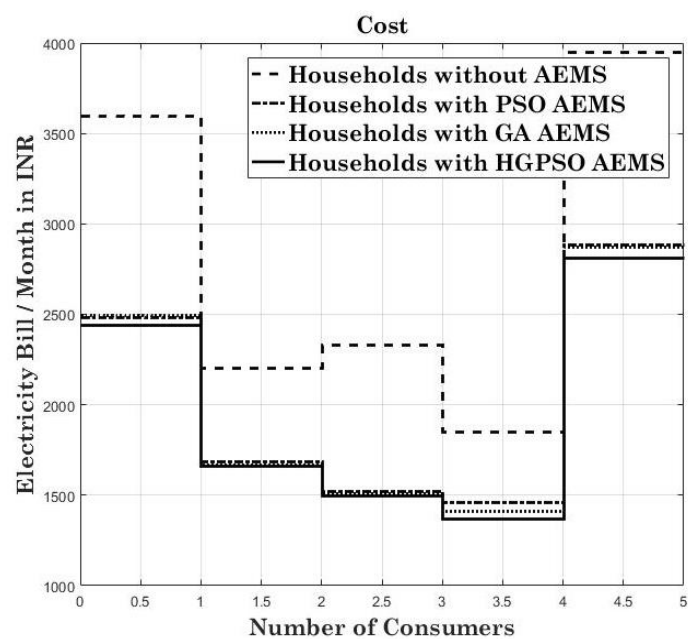

(b)

Figure 5. Cost curve for (a) single consumer (household 3) and (b) multiple consumers 
In our system we have used ESS in a flexible way such that ESS is charged form main grid in low pricing time (12:00 am to 06:00 am) as shown in Figure 6 and from RES in moderate pricing time (10:00 am to 03:00 pm). This cheap energy has been used for home appliances at peak pricing time as shown in Figure 7. Therefore, the energy available from RES is not only used for home appliances but for charging ESS also as shown in Figure 8 where as Table 3 shows the parameters of our ESS.

In this paper we have simulated our system with ESS of improved capacity and charging/discharging rate. ESS with better charging/discharging rate helps to reduce the electricity cost. Hence the effect of ESS in reducing electricity cost has been shown in Figures 9 and 10.

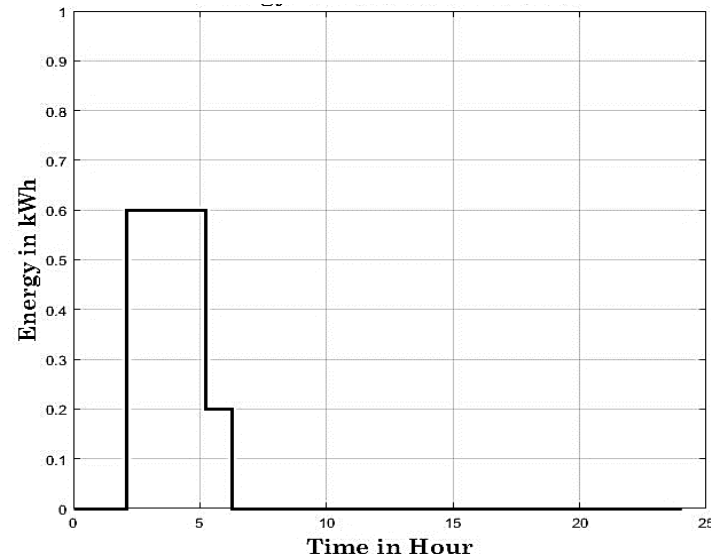

Figure 6. Energy stored in ESS from main grid

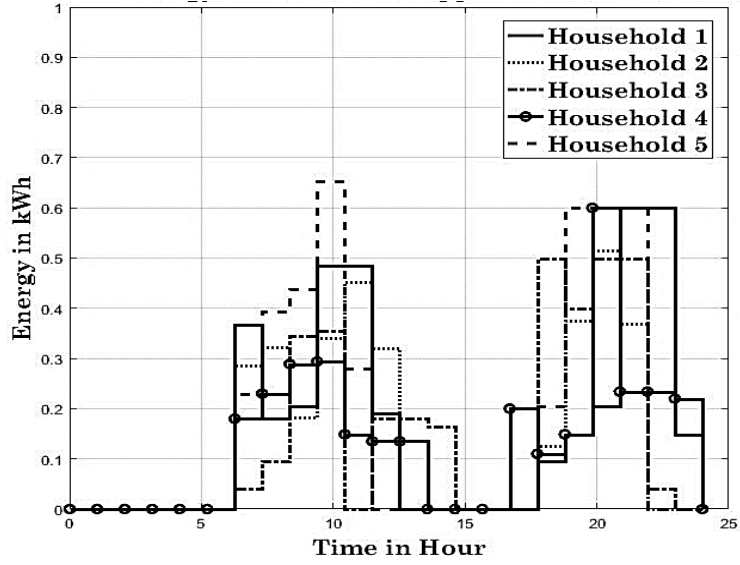

Figure 7. Energy used from ESS for home appliances

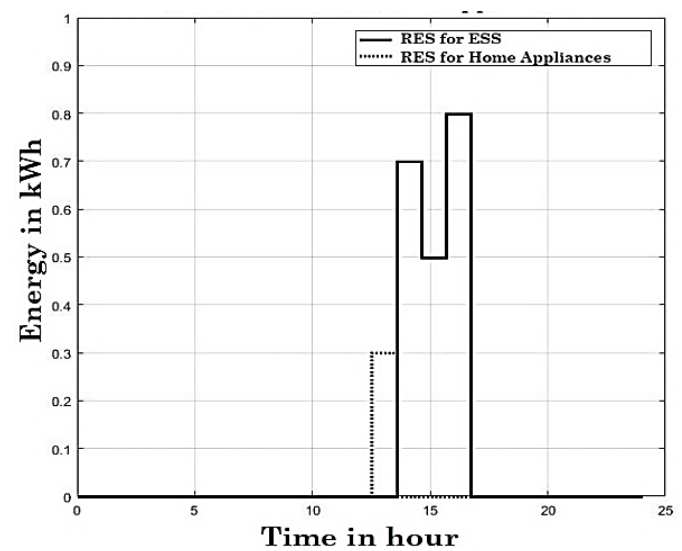

Figure 8. Use of RES

Table 3. ESS parameters

\begin{tabular}{cccc}
\hline Capacity of ESS & Min. Energy Level & Max. Energy Level & Charging/Discharging Rate \\
\hline $2 \mathrm{kWh}$ & $0.5 \mathrm{kWh}$ & $0.5 \mathrm{kWh}$ & $0.3 \mathrm{~kW}$ \\
\hline
\end{tabular}

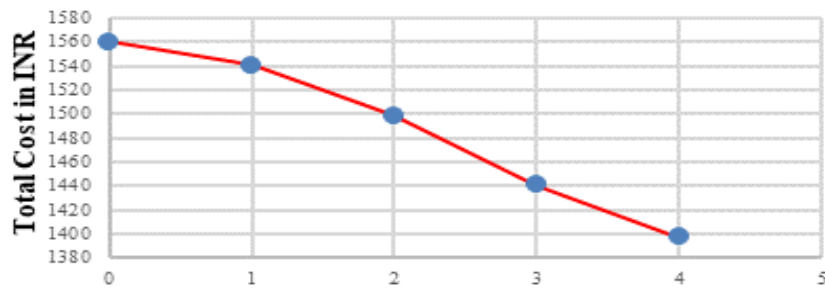

ESS Capacity in kWh

Figure 9. Effect of ESS capacity on cost reduction 


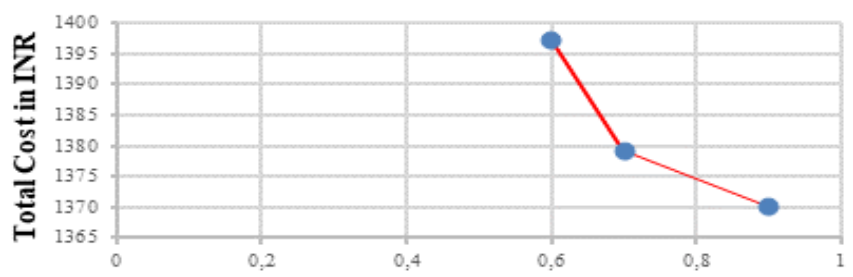

Charging/Discharging Rate (ESS Capacity : 4kWh)

Figure 10. Effect of ESS charge/discharge rate on cost reduction

\subsubsection{Waiting time}

Here, in this article consumers' preference has been considered as an important parameter to evaluate the efficiency of the proposed model. In Figure 11 it has been shown that with more flexible waiting time consumers will avail more benefit in terms of total cost. We have tried to achieve an AEMS using the proposed tariff and heuristic technique with minimum waiting time to maintain the comfort level of domestic consumers, which has been shown in Figure 12.

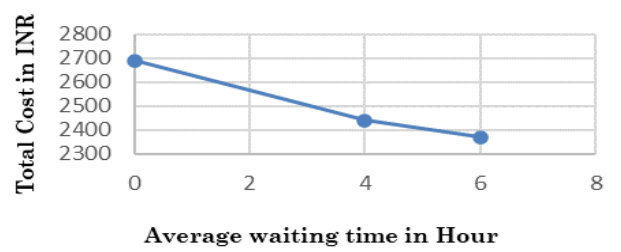

Figure 11. Trade off between cost and waiting time of appliances

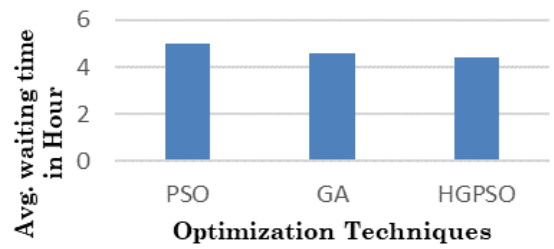

Figure 12. Reduction in waiting time using HGPSO AEMS

\subsection{Utility sectors' preference}

\subsubsection{PAR}

PAR is the ratio of the maximum aggregated load consumption over a certain time period and the average of the aggregated load.

$$
\operatorname{PAR}=\left(\sum_{i=1}^{N} \sigma_{a i}^{t}\right) \max / \frac{1}{T}\left(\sum_{i=1}^{N} \sigma_{a i}^{t}\right)
$$

The high PAR affects the grid stability and increases the electricity cost. While reduction in PAR improves the stability and reliability of the grid and reduces the electricity cost for the consumers. Improvement of PAR using HGPSO AEMS is shown in Figure 13 and Table 4.

Table 4. The performance of EMS on the basis of PAR

\begin{tabular}{ccc}
\hline & PAR & Reduction in PAR (in \%) \\
Without AEMS & With HGPSO AEMS & 43 \\
2.86 & 1.64 & 41 \\
3.64 & 2.16 & 33 \\
3.11 & 2.07 & 33 \\
3.69 & 2.46 & 35 \\
3.63 & 2.37 & \\
\hline
\end{tabular}




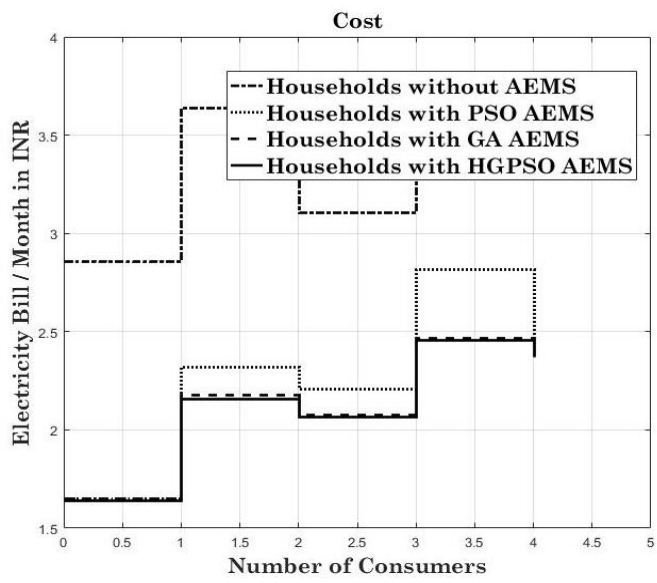

Figure 13. PAR reduction

\subsubsection{Valley filling and peak reduction}

Reducing the peak demand and reshaping the demand profile, robustness and reliability of the existing can be improved. The obtained result in terms of peak demand has been shown in Figure 14. The load demand from main grid has been shown in Figure 15 to point out the reduction in grid stress.

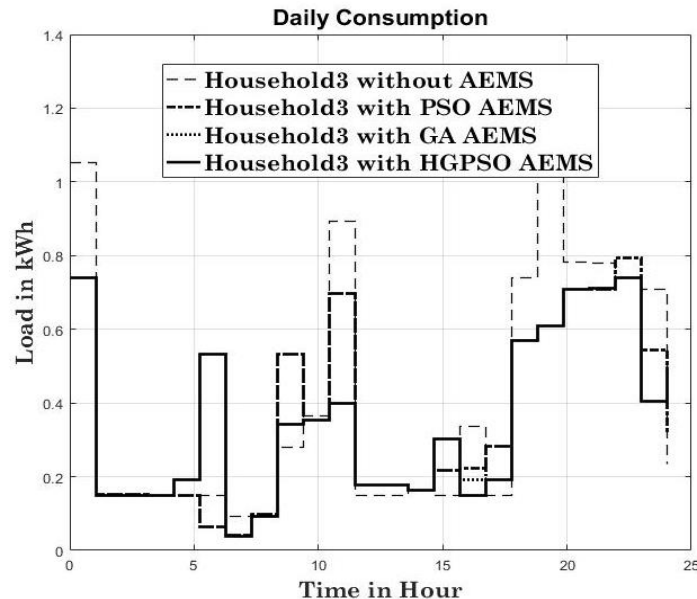

Figure 14. Peak reduction and valley filling with HGPSO for household 3

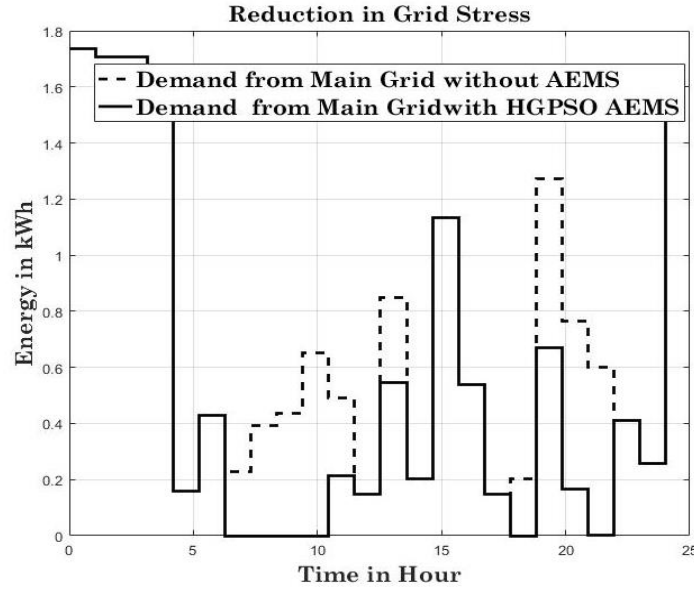

Figure 15. Load demand from main grid with and without HGPSO AEMS

Finally, the proposed HGPSO AEMS managed to achieve reduction in consumers' electricity expense and at the same time it reduces system peak load. The discussed technique can also be applied to a larger distribution system. Users are allowed to pre-plan their next day's consumption based on the desired demand profile and available tariff scheme using the illustrated application. Here a comparative study has been presented in Table 5 .

Table 5. Comparative study of results obtained from existing techniques and proposed technique

\begin{tabular}{|c|c|c|c|c|c|c|c|c|c|c|c|}
\hline Parameter & GA & PSO & DP & BPSO & $\mathrm{ACO}$ & FP & $\begin{array}{c}\text { Hybrid } \\
\text { Technique } \\
\text { (GA \& PSO) }\end{array}$ & EA & ILP & $\begin{array}{c}\text { Hybrid } \\
\text { Technique } \\
\text { (LP \& BPSO) }\end{array}$ & $\begin{array}{c}\text { Proposed } \\
\text { HGPSO }\end{array}$ \\
\hline PAR Reduction & $\checkmark$ & $\checkmark$ & $\checkmark$ & $\checkmark$ & $\checkmark$ & $x$ & $\checkmark$ & $x$ & $x$ & $x$ & $\checkmark$ \\
\hline Cost Reduction & $\checkmark$ & $\checkmark$ & $\checkmark$ & $\checkmark$ & $\checkmark$ & $\checkmark$ & $\checkmark$ & $\checkmark$ & $\checkmark$ & $\checkmark$ & $\checkmark$ \\
\hline $\begin{array}{l}\text { Consumers' } \\
\text { Preference }\end{array}$ & $x$ & $x$ & $x$ & $\checkmark$ & $\checkmark$ & $x$ & $x$ & - & $\checkmark$ & $\checkmark$ & $\checkmark$ \\
\hline Less Complexity & $x$ & $x$ & $x$ & $x$ & - & - & - & $x$ & $x$ & $x$ & $\checkmark$ \\
\hline
\end{tabular}




\section{CONCLUSION}

This paper has tried to address issues related to load management by scheduling the load, shifting the peak over 24 hours, reducing the overall consumption, utilizing the RES and ESS efficiently and incorporating the advanced tariff scheme, which in turn will led to efficient power consumption and costeffective power supply system. The objective of the case study is to generate an optimum load scheduling solution considering consumers' preference and convenience. A significant reduction in monthly electricity bill and peak load has been achieved which is an indication of improved grid stability. Therefore, it can be concluded that the utilities and federal agencies initiatives to save more energy and simultaneously to reduce peak load demand in all sectors can be supported by the proposed AEMS which is based on dynamic pricingbased tariff scheme and renewable energy integration.

\section{ACKNOWLEDGEMENTS}

Electrical Engineering Department and Digital Library of Jadavpur University have played the key role to enhance the research quality. Therefore, the authors would also like to thank Jadavpur University for providing the best study and research environment. The authors are also thankful to eastern region load dispatch centre (ERLDC) and west bengal renewable energy development agency (WBREDA) for providing required data and informations.

\section{REFERENCES}

[1] R. Sharifi, S. Fathi, and V. Vahidinasab, "A review on demand demand-side tools in electricity market," Renew. Sustain. Energy Rev., vol. 72, pp. 565-572, Jan. 2017, doi: 10.1016/j.rser.2017.01.020.

[2] C. W. Gellings, "Evolving practice of demand-side management," Journal of Modern Power System and Clean Energy. Springer, vol. 5, pp. 1-9, 2017, doi: 10.1007/s40565-016-0252-1.

[3] B. P. Esther and K. S. Kumar, "A survey on residential demand side management architecture, approaches, optimization models and methods," Renew. Sustain. Energy Rev. vol. 59, pp. 342-351, June 2016, doi: 10.1016/j.rser.2015.12.282.

[4] T. Logenthiran and S. D. Srinivasan, "Demand Side Management in Smart Grid Using Heuristic Optimization," IEEE Transactions on Smart Grid, vol. 3, no. 3, pp. 1244-1252, Sept. 2012, doi: 10.1109/TSG.2012.2195686.

[5] Z. Xu, Y. Gao, M. Hussain, and P. Cheng, "Demand Side Management for Smart Grid based on Smart Home Appliances with Renewable Energy Sources and an Energy Storage System," Hindawi, Mathematical Problems in Engineering, vol. 2020, p. 20, 2020, doi: 10.1155/2020/9545439.

[6] H. Ahmad, A. Ahmad, and S. Ahmad, "Efficient Energy Management in a Microgrid," International Conference on Power Generation Systems and Renewable Energy Technologies (PGSRET), IEEE, Sept. 2018, pp. 1-5, doi: 10.1109/PGSRET.2018.8685946.

[7] Y. Wang, L. Liu, R. Wennersten, and Q. Sun, "Peak shaving and valley filling potential of energy management system in highrise residential building," Energy Procedia, vol. 158, pp. 6201-6207, Feb. 2019, doi: 10.1016/j.egypro.2019.01.487.

[8] M. N. Naz, M. Naeem, M. Iqbal, and M. Imran, "Economically efficient and environment friendly energy management in rural area," J. Renew. Sustain. Energy, vol. 9, Jan. 2017, doi: 10.1063/1.4973713.

[9] F. Issi and O. Kaplan, "The Determination of Load Profiles and Power Consumptions of Home Appliances," Energies, MDPI, vol. 11, pp. 607-624, March 2018, doi: 10.3390/en11030607.

[10] S. Ahmad, M. Naeem, and A. Ahmad, "Low complexity approach for energy management in residential buildings," Int. Trans. Electr. Energ. Syst. Wiley Online Library, Aug. 2018, doi: 10.1002/etep.2680.

[11] S. A. Malik, T. M. Gondal, S. Ahmad, M. Adil, and R. Qureshi, "Towards Optimization Approaches in Smart Grid A Review," 2019 2nd Int. Conf. on Comp., Math. and Eng. Technologies (iCoMET), pp. 1-5, 2019, doi: 10.1109/ICOMET.2019.8673392.

[12] T. T. Nguyen, T. T. Ngoc, T. T. Nguyen, T. P. Nguyen, and N. A. Nguyen, "Optimization of location and size of distributed generations for maximizing their capacity and minimizing power loss of distribution system based on cuckoo search algorithm," Bulletin of Electrical Engineering and Informatics (BEEI), vol. 10, no. 4, pp. 1769-1776 ISSN: 2302-9285, August 2021, doi: 10.11591/eei.v10i4.2278.

[13] S. Ahmad, A. Ahmad, and Raziq Yaqub, "Optimized energy consumption and demand side management in smart grid," in Smart Technologies: Breakthroughs in Research and Practice, Hershey, PA, USA: IGI Global, pp. 550-574, June 2017, doi: 10.4018/978-1-5225-2589-9.ch025.

[14] H. M. Hussain, N Javaid, S. Iqbal, Q. U. Hasan, K. Aurangzeb, and M. Alhusein, "An Efficient Demand Side Management System with a New Optimized Home Energy Management Controller in Smart Grid," Energies, MDPI, vol. 11, pp. 1-28, Jan 2018, doi: 10.3390/en11010190.

[15] R. Yaqub, S. Ahmad, A. Ahmad, and M. Amin, "Smart energy-consumption management system considering consumers' spending goals (SEMS-CCSG)," Int. Trans. Electr. Energ. Syst. Wiley Online Library, 2015, doi: 10.1002/etep.2167.

[16] S. Ahmad, M. M. Alhaisoni, M. Naeem, A. Ahmad, and M. Altaf, "Joint Energy Management and Energy Trading in Residential Microgrid System," in IEEE Access, vol. 8, pp. 123334-123346, 2020, doi: 10.1109/ACCESS.2020.3007154.

[17] K. Zhang et al., "Incentive-Driven Energy Trading in the Smart Grid," in IEEE Access, vol. 4, pp. 1243-1257, 2016, doi: 10.1109/ACCESS.2016.2543841.

[18] A. Conchado and P. Linares, "The economic impact demand response programs on power system," A survey of the state of the art. Handb. Netw. Power Syst. I 2012, WP 02/2010, pp. 281-301, 2012, doi: 10.1007/978-3-642-23193-3_11.

[19] J. M. Lujano-Rojas, C. Monterio, R, Dufo Lopez, and J. L. Brnal Agustin, " Optimum residential load management strategy for real time pricing (RTP) demand response programs," Energy Policy, ELSEVIER, vol. 45, pp. 671-679, 2012, doi: 10.1016/j.enpol.2012.03.019.

[20] S. Joseph and E. A. Jasmin, "Demand response program for smart grid through real time pricing and home energy management system," International Journal of Electrical and Computer Engineering (IJECE), vol. 11 no. 5, pp. 4558-4567, Oct. 2021, doi: 10.11591/ijece.v11i5.pp4558-4567. 
[21] H. Khalid, F. R. Amin, and C. Chen, "Comparing the status and challenges of Demand Side Management (DSM) implementation in Asia-Pacific region: a case study of China's power sector," Energy Procedia, ELSEVIER, vol. 152, pp. 101-108, 2018, doi: 10.1016/j.egypro.2018.09.066.

[22] V. S. K. V. Harish and A. Kumar, "Demand side management in India: Action plan, policies and regulations," Renewable and Sustainable Energy Reviews, ELSEVIER, vol. 33, pp. 613-624, Feb 2014, doi: 10.1016/j.rser.2014.02.021.

[23] Z. Zhao, W. C. Lee, Y. Shin, and K. Song, "An Optimal Power Scheduling Method for Demand Response in Home Energy Management System," in IEEE Transactions on Smart Grid, vol. 4, no. 3, pp. 1391-1400, Sept. 2013, doi: 10.1109/TSG.2013.2251018.

[24] H. K. Nguyen, J. B. Song, and Z. Han, "Distributed Demand Side Management with Energy Storage in Smart Grid," in IEEE Trans. on Parallel and Distr. Sys. vol. 26, no. 12, pp. 3346-3357, Dec. 2015, doi: 10.1109/TPDS.2014.2372781.

[25] M. A. Khan, N. Javid, A. Mahmood, Z. A. Khan, and N. Alrajeh, "A generic demand-side management model for smart grid," Int. J. Energy Res, vol. 39, pp. 954-964, March 2015, doi: 10.1002/er.3304.

[26] D. Mahmood et al., "Realistic schedulingmechanism for smart homes," Energies 2016, vol. 9, p. 202, doi: 10.3390/en9030202.

[27] J. Ma, H. H. Chen, L. Song, and Y. Li, "Residential Load Scheduling in Smart Grid: A Cost Efficiency Perspective," in IEEE Transactions on Smart Grid, vol. 7, no. 2, pp. 771-784, March 2016, doi: 10.1109/TSG.2015.2419818.

[28] S. Rahim et al., "Exploiting heuristic algorithms to efficiently utilize energy management controllers with renewable energy sources," Energy Build. vol. 129, pp. 452-470, 2016, doi: 10.1016/j.enbuild.2016.08.008.

[29] J. T. Flores, W. C. Celeste, D. J. C. Coura, S. d. D. Rissino, H. R. O. Rocha, and R. E. N. Moraes, "Demand Planning in Smart Homes," in IEEE Latin America Transactions, vol. 14, no. 7, pp. 3247-3255, July 2016, doi: 10.1109/TLA.2016.7587627.

[30] M. B. Rasheed et al., "Real Time Information Based Energy Management Using Customer Preferences and Dynamic Pricing in Smart Homes," Energies 2016, vol. 9, no. 7, p. 542, doi: 10.3390/en9070542.

[31] P. Samadi, V. W. S. Wong, and R. Schober, "Load Scheduling and Power Trading in Systems with High Penetration of Renewable Energy Resources," in IEEE Transactions on Smart Grid, vol. 7, no. 4, pp. 1802-1812, July 2016, doi: 10.1109/TSG.2015.2435708

[32] K. Ma, T. Yao, J. Yang, and X. Guan, "Residential power scheduling for demand response in smart grid," Int. J. Electr. Power Energy Syst. 2016, vol. 78, pp. 320-325, 2016, doi: 10.1016/j.ijepes.2015.11.099.

[33] A. Ahmad et al., "An Optimized Home Energy Management System with Integrated Renewable Energy and Storage Resources," Energies 2017, vol. 10, p. 549, 2017, doi: 10.3390/en10040549.

[34] H. T. Dinh, J. Yun, D. M. Kim, K. Lee, and D. Kim, "A Home Energy Management System With Renewable Energy and Energy Storage Utilizing Main Grid and Electricity Selling," in IEEE Access, vol. 8, pp. 49436-49450, 2020, doi: 10.1109/ACCESS.2020.2979189.

[35] S. M. Hameed, H. K. AL-Qaysi, A. S. Kaittan, and M. H. Ali, "Evaluation of electrical load estimation in Diyala governorate (Baaquba city) based on fuzzy inference system," International Journal of Electrical and Computer Engineering (IJECE), vol. 11, no. 5, pp. 3757-3762, October 2021, doi: 10.11591/ijece.

[36] M. Suresh, P. Maniraj, S. Sundar, T. Logeswaran, and P. Tamilarasu, "Peak Time Load Management in Domestic Sector," Int. J. of Innov. Tech. and Exploring Engineering (IJITEE), vol. 9, no. 1, pp. 2278-3075, Nov. 2019, doi: 10.35940/ijitee.A5221.119119.

[37] A. Ganguly, K. Goswami, A. Mukherjee, and A. Kumar Sil, "Short-Term Load Forecasting for Peak Load Reduction Using Artificial Neural Network Technique," Advances in Computer, Communication and Control Proceedings of ETES 2018 Lecture Notes in Networks and Systems, Springer, vol. 41, pp. 551-559, 2018, doi: 10.1007/978-981-13-3122-0_56.

[38] K. Goswami, A. Ganguly, and A. Kumar Sil, "Comparing Univariate and Multivariate Methods for Short Term Load Forecasting," 2018 International Conference on Computing, Power and Communication Technologies (GUCON), 2018, pp. 972-976, doi: 10.1109/GUCON.2018.8675059.

\section{BIOGRAPHIES OF AUTHORS}

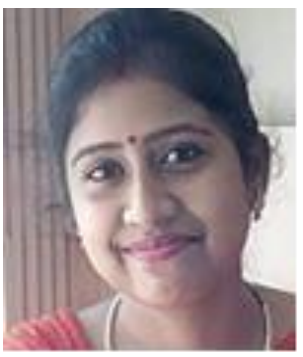

Kuheli Goswami (D) 8 SC P (Non-Member) received her B. Tech degree in Electrical Engineering from West Bengal University of Technology (presently known as Maulana Abul Kalam Azad University of Technology), India and M. Tech degree in Electrical Power from University of Calcutta (UCSTA), India. She is pursuing her $\mathrm{PhD}$ degree in Electrical Engineering from Jadavpur University, India. She is currently working as an Assistant Professor at the Department of Electrical Engineering, Brainware Group of Institutions (MAKAUT), India. Her area of research interests includes Demand Side Management, Peak Load Reduction and management, Renewable Energy integration. She can be contacted at email: kgg2017juresearch@gmail.com.

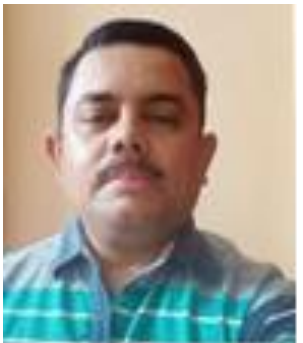

Dr. Arindam Kumar Sil (D) 8d SC P (Non-Member) received his B.E degree in Electrical and Electronics Engineering from Karnataka University, Dharwad, India and M.E degree in Power Engineering from Jadavpur University, India. He has obtained his $\mathrm{PhD}$ degree in Electrical Engineering from Jadavpur University, India. He is currently working as an Associate Professor at the Department of Electrical Engineering, Jadavpur University, India. His area of research interests includes Power System Planning, Peak Load Management, Renewable Energy Integration to Grid. He can be contacted at email: ak_sil@yahoo.co.in. 